\title{
Determination of serum aluminum, platelet aggregation and lipid peroxidation in hemodialyzed patients
}

\author{
T.J.C. Neiva ${ }^{1}$, \\ A.L. Benedetti \\ S.M.C.N. Tanaka ${ }^{3}$, \\ J.I. Santos ${ }^{1}$ \\ and E.A. D'Amico ${ }^{4}$
}

\author{
1Departamento de Análises Clínicas, U niversidade Federal de Santa Catarina, \\ Florianópolis, SC, Brasil \\ ${ }^{2}$ Curso de Especialização em Hematologia, U niversidade Estadual de Ponta Grossa, \\ Ponta Grossa, PR, Brasil \\ ${ }^{3}$ Departamento de Tecnologia Q uímica, Universidade Federal do Maranhão, \\ São Luís, MA, Brasil \\ ${ }^{4}$ Fundação Pró-Sangue Hemocentro de São Paulo, São Paulo, SP, Brasil
}

\section{Correspondence \\ T.J.C. Neiva \\ Disciplina Hematologia Clínica \\ Departamento de Análises Clínicas \\ CCS, UFSC \\ 88010-970 Florianópolis, SC \\ Brasil \\ E-mail: t.j.c.n@uol.com.br}

Publication supported by FAPESP

Received June 8, 2001

Accepted January 25, 2002

\section{Abstract}

Aluminum $\left(\mathrm{Al}^{3+}\right)$ overload is frequently associated with lipid peroxidation and neurological disorders. Aluminum accumulation is also reported to be related to renal impairment, anemia and other clinical complications in hemodialysis patients. The aim of the present study was to determine the degree of lipid peroxidation, platelet aggregation and serum aluminum in patients receiving regular hemodialytic treatment. The level of plasma lipid peroxidation was evaluated on the basis of thiobarbituric acid reactive substances (TBARS). Mean platelet peroxidation in patients undergoing hemodialysis was significantly higher than in normal controls $(2.7 \pm 0.03$ vs $1.8 \pm 0.06 \mathrm{nmol} / \mathrm{l}$, $\mathrm{P}<0.05$ ). Platelet aggregation and serum aluminum levels were determined by a turbidimetric method and atomic absorption spectrophotometry, respectively. Serum aluminum was significantly higher in patients than in normal controls $(44.5 \pm 29 v s 10.8 \pm 2.5 \mu \mathrm{g} / \mathrm{l}, \mathrm{P}<0.05)$. Human blood platelets were stimulated with collagen $(2.2 \mu \mathrm{g} / \mathrm{ml})$, adenosine diphosphate $(6 \mu \mathrm{M})$ and epinephrine $(6 \mu \mathrm{M})$ and showed reduced function with the three agonists utilized. No correlation between aluminum levels and platelet aggregation or between aluminum and peroxidation was observed in hemodialyzed patients.

\section{Introduction}

Chronic renal failure is characterized by a progressive and irreversible loss of renal function. Aluminum intoxication has been a serious problem in some dialysis units (1). Nowadays its pathogenesis is well understood and there is general agreement that aluminum overload occurs due to aluminum from the dialysate and to aluminum used for

\author{
Key words \\ - Aluminum \\ - Peroxidation \\ - Hemodialysis \\ - Platelets
}

phosphate binders (2). This condition generally occurs in long-term dialysis patients and is characterized by speech abnormalities, stuttering, seizures, myoclonus, personality changes, hearing loss, visual hallucinations, and accelerated aging. Aluminum accumulation is also thought to be related to renal impairment, anemia and other clinical complications in hemodialysis patients $(1,3)$. Furthermore, these patients present enhanced 
levels of plasma lipid peroxidation compared to healthy individuals (4) and also develop atherosclerosis (5). Some manifestations, such as accelerated aging and atherosclerosis, may be related to the hyperproduction of free radicals $(6,7)$.

Although aluminum has no redox capacity, it can stimulate tissue lipid peroxidation in animal models (8) and the cytotoxic end products of lipid peroxidation may cause platelet dysfunction. Nevertheless, reactive oxygen species (ROS) such as superoxide anions, hydrogen peroxide and hydroxyl radicals are generated by platelets and can damage the plasma membranes by triggering polyunsaturated fatty acid peroxidation, membrane receptor and enzyme inactivation, polysaccharide depolymerization and protein cross-linking and fragmentation (9).

Previous studies have reported activation of phospholipase $\mathrm{A}_{2}$ and phospholipase $\mathrm{C}$ by ROS (10). Furthermore, aluminum in combination with fluoride, forming the fluoraluminate complex (11), activates phospholipase $A_{2}$ and $B$-thromboglobulin release in human blood platelets (12). We have observed that aluminum induces lipid peroxidation and aggregation of human blood platelets (13). All of these events probably constitute the basis for the abnormalities found in chronic renal failure. The aim of the present study was to determine the degree of lipid peroxidation and platelet aggregation and the presence of aluminum in chronic renal failure patients submitted to long-term hemodialysis.

\section{Material and Methods}

Reagents

Collagen, adenosine diphosphate and epinephrine were purchased from Chronolog Corporation, Havertown, PA, USA, while malondialdehyde bis(diethyl acetal) was obtained from Aldrich Chemical Company Inc.
(Milwaukee, WI, USA). All other chemicals were of the highest quality available and were obtained from commercial sources.

\section{Patients}

The study was conducted at the Dialysis Center of Hospital de Caridade, and included 55 patients (aged 18 to 76 years) on maintenance hemodialysis who gave written informed consent to participate. The study was approved by the Ethics Committee of the University Hospital, UFSC, Florianópolis, $\mathrm{SC}$, Brazil. All patients were submitted to hemodialysis at the same hospital for $4 \mathrm{~h}$, three times a week and the water used was treated by the same dialytic process. A cellulose acetate dialyzing membrane was employed. The etiology of renal failure included chronic glomerulonephritis (15\%), hypertensive nephrosclerosis $(61 \%)$, polycystic renal disease ( $9 \%$ ), reflux nephropathy (2\%), and indeterminate causes (2\%). The water used for the dialysis fluid was treated by deionization. The patients did not ingest acetylsalicylic acid or any other nonsteroidal anti-inflammatory drug for 3 weeks prior to the study and did not receive any aluminumcontaining phosphate buffer. None of the patients received blood transfusion during the study or in the preceding week. Heparin was used as the anticoagulant during hemodialysis. Mean patient hematocrit was $27.7 \pm$ $3.8 \%$, and plasma creatinine was $9.6 \pm 19.2$ $\mathrm{mg} / \mathrm{dl}$. The control group consisted of healthy donors (10 males and 10 females) aged 20 to 41 years, all were drug-free with mean hematocrit and creatinine values of $45 \pm 4.4 \%$ and $0.8 \pm 0.2 \mathrm{mg} / \mathrm{dl}$, respectively.

\section{Platelet isolation}

Human blood platelets were collected into plastic tubes containing $3.8 \%$ sodium citrate. Platelet-rich plasma was obtained by centrifugation of citrated blood at room temperature for $6 \mathrm{~min}$ at $180 \mathrm{~g}$. 


\section{Measurement of platelet aggregation}

Platelet aggregation was determined by the turbidimetric method of Born and Cross (14) using a Net Lab aggregometer. Aliquots of $450 \mu \mathrm{l}$ of a platelet suspension were pipetted into small cuvettes and stirred at a constant speed of $1,000 \mathrm{rpm}$ at $37^{\circ} \mathrm{C}$. The aggregation-inducing agents used were $6 \mu \mathrm{M}$ adenosine diphosphate, $6 \mu \mathrm{M}$ epinephrine, and $2.2 \mu \mathrm{g} / \mathrm{ml}$ collagen. The extent of aggregation (\%) was recorded continuously for 5 min after addition of the agonist.

\section{Measurement of lipid peroxidation (TBARS test)}

TBARS tests were carried out on plasma by the method of Buege and Aust (15). Briefly, $200 \mu 112 \%$ trichloroacetic acid and $450 \mu 1$ 0.3 M HEPES, pH 7.4, were added to the plasma samples. The samples were centrifuged at $900 \mathrm{~g}$ for $10 \mathrm{~min}$, and $450 \mu \mathrm{l}$ was extracted from the supernatant, to which an equal volume of $0.2 \mathrm{M}$ TBA plus $1 \%$ butylated hydroxytoluene was added. This suspension was then incubated at $100^{\circ} \mathrm{C}$ for 15 $\mathrm{min}$, and cooled to room temperature. Spectrophotometric absorption was then measured at $532 \mathrm{~nm}$ and malondialdehyde (MDA) concentration was calculated. Appropriate standard curves were prepared using malondialdehyde bis(diethyl acetal) as the MDA source. TBARS values are reported as $\mathrm{nmol} / \mathrm{l}$ plasma.

\section{Measurement of aluminum}

Serum was removed and stored at $-20^{\circ} \mathrm{C}$ for a period of 60 days. Serum aluminum concentration was determined by atomic absorption spectrophotometry (16).

\section{Statistical analysis}

The Mann-Whitney test was employed to estimate differences between groups, and the Spearman correlation coefficient was determined. Differences were considered to be significant when the probability was $\mathrm{P}<0.05$. The statistical program Instat 2 was used for analysis.

\section{Results ands D iscussion}

The objective of the present study was to determine serum aluminum, peroxidation and platelet aggregation in patients receiving regular hemodialysis treatment. We observed a significant reduction in platelet aggregation in these patients compared with the healthy control group (Table 1). This result is not due to the differences in platelet concentrations of the two groups, since their mean values were not significantly different. On the other hand, the hematocrit value has been shown to interfere with platelet aggregation. It is known that an increase in the value of this parameter can inhibit platelet function in vitro since a greater amount of citrate is left in the serum, causing a reduction in calcium levels and consequently leading to platelet inhibition (17). The patients of our study presented hematocrit values of $27.7 \%$, a fact that invalidates this possibility. However, hypofunction of platelet aggregation may have occurred in hemodialyzed patients since a higher tendency towards a reduction in platelet function was observed among them (Table 1). Indeed many chronic renal failure patients present a reduction in platelet function (18-21). However, the

Table 1. Platelet concentration and aggregation.

\begin{tabular}{lcr}
\hline & Control $(\mathrm{N}=20)$ & Patients $(\mathrm{N}=55)$ \\
\hline Platelets $\times 10^{3} / \mathrm{mm}^{3}$ & $206.44 \pm 48.2$ & $200.59 \pm 52.4$ \\
Aggregation & $77.5 \pm 7.2$ & $52.0 \pm 21.0^{*}$ \\
Collagen $(2.2 \mu \mathrm{g} / \mathrm{ml})$ & $76.5 \pm 6.3$ & $48.5 \pm 23.0^{*}$ \\
Epinephrine $(6 \mu \mathrm{M})$ & $78.0 \pm 8.4$ & $54.0 \pm 20.5^{*}$ \\
ADP $(6 \mu \mathrm{M})$ & & \\
\hline Platelets were stimulated with collagen, epinephrine and adenosine diphosphate \\
(ADP). Data are reported as means \pm SD. \\
$*$ P $<0.05$ compared to the control group (Mann-Whitney test).
\end{tabular}


mechanisms involved in this process have yet to be understood. Sreedhara et al. (18) observed a reduction in the availability of GPIIb-IIIa membrane receptors in uremic patients. According to Gralnick et al. (19), the reduced platelet aggregation could be ascribed to a reduction in von Willebrand factor levels. In our study, the primary aggregation response to the three agonists studied displayed normal levels (data not shown), ruling out the possibility of a problem at the receptor level. However, the secondary aggregation response was significantly inhibited, suggesting in vivo activation in these patients, with the consequent plasma release of peroxidation products. Indeed, a significant increase in the concentration of plasma MDA was observed in these patients (Table 2).

Among patients presenting chronic renal

Table 2. Serum aluminum and malondialdehyde (MDA) production.

\begin{tabular}{lcr}
\hline & $\begin{array}{c}\text { Control } \\
(\mathrm{N}=20)\end{array}$ & \multicolumn{1}{c}{$\begin{array}{c}\text { Patients } \\
(\mathrm{N}=55)\end{array}$} \\
\hline Aluminum $(\mu \mathrm{g} / \mathrm{l})$ & $10.8 \pm 2.5$ & $44.5 \pm 29.0^{*}$ \\
MDA (nmol/l) & $1.8 \pm 0.06$ & $2.7 \pm 0.03^{*}$
\end{tabular}

TBARS tests were carried out on plasma and aluminum concentration was measured in serum. Data are reported as means \pm SD.

$* \mathrm{P}<0.05$ compared to the control group (MannWhitney test).

Table 3. Spearman correlation coefficients between aluminum concentration and malondialdehyde (MDA) production and platelet aggregation.

Aluminum

MDA

Platelet aggregation

Collagen

Adenosine diphosphate

Epinephrine

$-0.15$

0.13

0.23

0.32

No significant correlation was found $(\mathrm{P}>0.05, \mathrm{~N}=$ 55). failure, whether undergoing hemodialysis or not, several factors such as the lipid composition of platelet membranes (20), lipoprotein abnormalities $(6,22)$, types of dialysis membranes (23) and accumulation of aluminum can trigger platelet activation. It has been reported in the literature that chronic renal failure patients undergoing prolonged hemodialysis show increased levels of aluminum in their sera (24-27). Although this metal does not display redox capacity, it is capable of inducing peroxidation in cerebral tissue (8) and platelet aggregation in vitro (13). In addition, a high level of this metal is also associated with pathologies such as Alzheimer's encephalopathy, amyotrophic lateral sclerosis and ageing $(28,29)$. Vecino et al. (29) reported an increase in the cholesterol/phospholipid ratio in the platelets of uremic patients, which was correlated with a hyperreactive state, even though a platelet hypofunction was detected in vitro.

In the present study we sought to measure the aluminum levels of hemodialysis patients and the implication such levels could have for hemostasis function. The hemodialysis patients exhibited significantly higher aluminum levels than the controls. However, we found no correlation between high aluminum content and peroxidation or platelet aggregation (Table 3), as reported in other studies $(13,30)$. It is noteworthy that the increased plasma peroxidation events do not reflect the production of MDA exclusively from platelets, but also from other cell elements such as erythrocytes (6) and leukocytes (7). The results reported in the latter study also suggested that patient platelet dysfunction is the result of a multitude of factors rather than the consequence of aluminum accumulation. However, although a clear correlation between aluminum and platelet dysfunction is yet to be demonstrated, it is reasonable to suppose that in vivo accumulation of aluminum may increase the effects of ROS occurring in these patients. Although aluminum has no redox capacity it can cause 
alterations at the membrane level, facilitating lipid peroxidation. Gutteridge et al. (30) have shown that aluminum salts do not directly stimulate peroxidation, but instead accelerate iron- and hydrogen peroxide-dependent lipid peroxidation in phospholipid liposomes and human erythrocyte membranes. On the other hand, superoxide and hydrogen peroxide are known to induce plate- let aggregation and these cells are known to produce superoxide and hydrogen peroxide (31).

Our data show that patients undergoing hemodialysis present platelet dysfunction and lipid peroxidation. They also demonstrate that increased levels of serum aluminum do not correlate with lower platelet aggregation.

\section{References}

1. Salahudeen AK, Deogaygay B, Fleischmann E \& Bower J D (2000). Race-dependent survival disparity on hemodialysis: higher serum aluminum as an independent risk factor for higher mortality in whites. American J ournal of Kidney Diseases, 36: 1147-1154.

2. Yates LA, Soffer O \& Gropper SS (2000). Phosphate binders do not compromise the copper status of adult renal disease patients on hemodialysis. Biological Trace Element Research, 76: 1-12.

3. Doll R (1993). Alzheimer's disease and environmental aluminum. Age and Ageing, 22: 138-153.

4. Toborek M, Wasik T, Drózdz M, Klin M, Magner-Wroble $K \&$ Kopieczna-Grzebienniak E (1992). Effect of hemodialysis on lipid peroxidation and antioxidant system in patients with chronic renal failure. Metabolism, 41: 1229-1232.

5. Lindner A, Charra B, Sherrand D \& Seribner BH (1974). Accelerated atherosclerosis in prolonged maintenance hemodialysis. New England J ournal of Medicine, 290: 697-701.

6. Boran $M$, Küçükaksu C, Balk M \& Cetin S (1998). Red cell lipid peroxidation and antioxidant system in hemodialyzed patients: influence of recombinant human enythropoietin (r-HuEPO) treatment. International Urology and Nephrology, 30: 507512.

7. Anderton J G, Thomas TH \& Wilkinson R (1996). Increased susceptibility to membrane lipid peroxidation in renal failure. Nephron, 74: 373-377.

8. Fraga GC, Oteiza PI, Golub MS, Gerswin ME \& Keen CL (1990). Effects of aluminum on brain lipid peroxidation. Toxicology, 51: 213-219.

9. Salvemini $D \&$ Botting R (1993). Modulation of platelet function by free radicals and free radical scavengers. Trends in Pharmacological Sciences, 14: 36-42.
10. Goldman R, Ferber E \& Zort U (1992). Reactive oxygen species are involved in the activation of cellular phospholipase $\mathrm{A}_{2}$. FEBS Letters, 3: 190-192.

11. Rendu F, Lebet M, Tenza D \& ToledanoLevy S (1990). How does fluoraluminate activate human platelets? Biochemical J ournal, 265: 343-349.

12. Stasi M, Gresele P, Porcelati S, Quero E, Nenci G \& Goracci G (1992). Activations of phospholipase $A_{2}$ and thromboglobulin release in human platelets: comparative effects of thrombin and fluoraluminate stimulation. Biochimica et Biophysica Acta, 1124: 279-287.

13. Neiva TJ C, Fries DM, Monteiro HP, D'Amico EA \& Chamone DAF (1997). Aluminum induces lipid peroxidation and aggregation of human blood platelets. Brazilian J ournal of Medical and Biological Research, 30: 599-604.

14. Born $G \&$ Cross MJ (1963). The aggregation of blood platelets. J ournal of Physiology, 168: 178-195.

15. Buege J A \& Aust SD (1978). Microsomal lipid peroxidation. Methods in Enzymology, 52: 302-310.

16. Gorsky J E \& Dietz AA (1978). Determination of aluminum in biological samples by atomic absorption spectrophotometry with a graphite fumace. Clinical Chemistry, 24: 1485-1490.

17. Kelton J G, Powers P, J ulian J , Boland V, Carter CJ , Gent M \& Hirsh J (1980). Sexrelated differences in platelet aggregation: influence of the hematocrit. Blood, 56: 38-41.

18. Sreedhara R, Itagaki I \& Hakim RM (1996). Uremic patients have decreased shearinduced platelet aggregation mediated by decreased availability of glycoprotein IIbIIla receptors. American J ournal of Kidney Diseases, 27: 355-364.

19. Gralnick HP, McKeown LP, Williams SB, Shafer BC \& Pierce L (1988). Plasma and platelet von Willebrand factor defects in uremia. American J ournal of Medicine, 85: 806-810.

20. Smits J H, van der Linden J , Blankestijn PJ \& Rabelink TJ (2000). Coagulation and haemodialysis access thrombosis. Nephrology, Dialysis, Transplantation, 15: 17551760.

21. Tan CW, Yount RD \& Quintal R (2000). Percutaneous recanalization of thrombosed dialysis shunts. J ournal of the Louisiana State Medical Society, 152: 559562.

22. Holvoet $\mathrm{P}$, Donck J, Landeloos M, Brouwers $\mathrm{E}$, Luijtens $\mathrm{K}$, Arnout J, Lesaffre E, Vanrenterghem Y \& Collen D (1996). Correlation between oxidized low density lipoproteins and von Willebrand factor in chronic renal failure. Thrombosis and Haemostasis, 76: 633-639.

23. Dasgupta A, Hussain S \& Ahmad S (1992). Increased lipid peroxidation in patients on maintenance hemodialysis. Nephron, 60 : 56-59.

24. Zachee $P$, Boogaerts $M A$, Lins R, Daelemans $R$, Henckens $M \&$ De Broe $M E$ (1990). Erythropoietin, aluminum, and anemia and patients on haemodialysis. Lancet, 335: 1038-1039.

25. Berend $K$, van der Voet $G \&$ Boer $W$ (2001). Acute aluminum encephalopathy in a dialysis center caused by a cement mortar water distribution pipe. Kidney International, 59: 746-753.

26. Van Landeghem GF, D'Haese PC, Lamberts LV \& De Broe ME (1997). Competition of iron and aluminum for transferrin. The molecular basis of aluminum deposition in iron-overloaded dialysis patients. Experimental Nephrology, 5: 239-245.

27. Cannata J B, Olaizola IR, Gomez-Alonso C, Menendez-Fraga $\mathrm{P}$, Alonso-Suarez $\mathrm{M}$ \& Dias-Lopez J B (1993). Serum aluminum transport and aluminum uptake in chronic renal failure: role of iron and aluminum 
metabolism. Nephron, 65: 141-146.

28. Harington $C R$, Wischik CM, M cArthur FK, Taylor GA, Edwardson J A \& Candy J M (1994). Alzheimer's-like changes in protein processing: association with aluminum accumulation in brains of renal dialysis patients. Lancet, 343: 993-997.

29. Vecino A, Navarro-Antolin J, Teruel J,
Navarro J \& Cesar J (1998). Lipid composition of platelets in patients with uremia. Nephron, 78: 271-273.

30. Gutteridge J M, Quilan GL \& Halliwell B (1988). Action of lead II and aluminum III ions on iron stimulated lipid peroxidation in liposomes, erythrocytes and rat liver microsomal fractions. Biochimica et
Biophysica Acta, 962: 196-200.

31. Caccese D, Pratico D, Ghiselli A, Natoli S, Pignatelli P, Sanguini V, Iuliano L \& Violi F (2000). Superoxide anion and hydroxyl radical release by collagen-induced platelet aggregation: role of arachidonic acid metabolism. Thrombosis and Haemostasis, 83: 485-490. 